\title{
A STUDY ON TEMPERATURE DISTRIBUTION OF THE HIGH VOLTAGE PORCELAIN INSULATOR STRING
}

\author{
LE VAN DAI \\ Industrial University of Ho Chi Minh City, Ho Chi Minh City, Vietnam \\ levandai@iuh.edu.vn
}

\begin{abstract}
Nowadays, porcelain string insulators are commonly used in high voltage transmission lines. The study of temperature distribution is extensively performed in the design and development of high voltage insulations. As known, the infrared technology has opened the door to a variety of applications and especially it is also used as a kind of non-contact remote detection technology which has the advantage for detecting high voltage faulty porcelain insulator. Thanks to it, this paper uses the infrared technology to investigate the temperature distribution of the $220 \mathrm{kV}$ power grid insulator string. The experiments were done in climate chamber to study. Firstly, determining the thermal stability time of the high voltage porcelain insulator called XP-70 type composing of 14 pieces under the tested voltage of $127 \mathrm{kV}$ based on the temperature and voltage distribution. And then the temperature distribution along the normal and fault insulator string experiments. The experimental results show that it may detect and compare the insulator metal cap temperature of faulty insulator in the porcelain insulator string and determine the location of them. And especially based on the unchangeable voltage distribution, it may detect the temperature distribution characteristic for the fault insulator string. Therefore, this research results can provide a reference to detect the faulty porcelain insulator strings
\end{abstract}

Keywords. Infrared technology, temperature distribution, voltage distribution, porcelain insulator string.

\section{INTRODUCTION}

Insulator is one of the basic insulation components of the power system, and since ceramic insulators costeffective, easy to install and replace, have been widely used in China and the world. But for some reason, the electrical insulation properties of some high-voltage porcelain insulators may be severely degraded or even completely lost, namely the deterioration of electrical insulation properties, the insulator with a serious declined of electrical insulation properties is known as faulty insulators. The existence of faulty porcelain insulator reduces the overall effective creep-age distance of insulator strings, and the probability of flashover short circuit of insulator strings will be greatly increased, it is also there is a possibility that the faulty insulator crack (burst) and cause insulator (wire) drop. The existence of faulty insulator is one of the grid security risks, a serious threat to the safety of power system operation. Methods for faulty porcelain insulators detection fall into the categories of electrical, acoustic and visual. This can also be divided into two categories, contact detection and remote non-contact detection. Electrical detection, including such as electric field measurement, voltage distribution, electrical resistance, leakage current .etc. [1]-[6], must be exposed to high electric field, which belongs to the contact-type detection. The acoustic, such as ultra-sonic detection, corona detection, Radio Frequency (RF) Signals etc. [7]-[10], and enhanced visual method, such as ultra violet, infra-red technology .etc. [11]-[14], can be used remotely and must not be exposed to high electric field, which belongs to the noncontact-type detection. The Electrical detection is most commonly relied upon, but essentially employs hands on techniques. Because of the large number and high altitude, high voltage faulty insulator detection by using traditional manual method will be a time consuming and costly exercise. In contrast, remote non-contact detection is even more convenient, fast, and away from high voltage electric field also makes workers more secure.

Infrared detection which is increasingly being applied to electrical equipment detection [15]-[17] is one of remote non-contact detection methods. An early infra-red imaging trial in 1971 in England was used to detect defective joints and fittings [14]. Infrared detection is based on the temperature distribution of the object to be detected, and insulator string temperature distribution is the basis of the faulty insulator infrared detection, so first need to study the temperature distribution of the insulator to achieve remote non-contact infrared detection technology for detection of insulator. Many research studies have been carried out on the 
temperature distribution on the porcelain insulator string. Temperature distribution on the surface of an energized polluted insulator has been measured using infra-red thermo-vision techniques, and the tests results show that the maximum temperature area of the energized insulator could be at the regions around the pin [13]. The possibility of remote detection of detective porcelain insulators has been investigated in [14], and it considered that the mechanisms involved should be understand first in order to develop more cost effective diagnostic techniques. Voltage and temperature distributions along the semiconducting glaze insulator string have been calculated on the basis of an equivalent circuit in [18], and experiment has been done in the laboratory to verify the calculation results (and the calculation results agreed well with the experiment results obtained in a laboratory test). Temperature distribution along a glass insulator to different pollution levels was studied with a proposed numerical procedure in [19]. The surface temperature distribution along the uniformly contaminated insulator was studied in [20]. The failure characteristics of suspension-type porcelain insulator was studied in [21] and it was found that the combined thermal and mechanical tests have a close relationship to the dielectric strength of the porcelain body. The temperature rise of transmission line insulators heated by conductor is investigated in [22], remarkable temperature rise was not observed at porcelain and cement of insulators in spite of the high conductor temperature. The characterization of polymeric insulators using thermal and UV Imaging under laboratory conditions was studied in [23-24]. The existing research results mainly focused on a single insulator (individual) or the contamination insulator surface temperature distribution aspect, but as a whole insulator string temperature distribution is less studied.

The alteration of electric field, voltage, and temperature distribution may affect the insulator in terms of the life span and ultimately lead to the insulation breakdown after a certain period of time. Therefore, at present, several numerical methods such as finite difference, finite element, charge simulation method, finite integration technique and boundary element method can be used to study the electric field, voltage, and temperature distributions along insulators [25-30]. The infrared technology has opened the door to a variety of applications and especially it is also used as a kind of non-contact remote detection technology which has the advantage for detecting high voltage faulty porcelain insulator. Thanks to it, this paper takes the $220 \mathrm{kV}$ power grid insulator string as the research object. Tests with sound and fault insulator strings with different resistance deterioration insulators were studied experimentally to discover the insulator string temperature distribution law. Experimental results show that the faulty insulators temperature rise in a whole insulator string manifestations obvious abnormality, and it can be used to detect the faulty insulators. Results of this study can provide a reference for detection of faulty insulator using infrared technique.

Basically, this paper divides 5 sections, in which Introduction section reviews the problems associated with the researched topic, recalls some solution orientations, and proposes novel method and the motivation. Section 2 deals with the theoretical associated problem. Section 3 presents the main contents involving the experimental set-up. The experimental cases, result, and discussion have been stated in Section 4. Finally, the conclusions are given in Section 5.

\section{THEORETICAL PROBLEM}

The investigation was carried out on the type of porcelain disc insulator. Fig. 1 shows actual insulator disc model and technical parameters. The idea of simple heat transfer processes affecting the temperature distribution of an insulator string is shown in Fig. 2. The mathematical expression for temperature distribution can express as follows [31]:

$$
C \frac{d T}{d t}=P_{i n}+P_{s}-P_{o u t}+P_{c}-P_{r}
$$

in which, $C$ is the heat capacity of an insulator, $t$ is time, $P_{i n}$ is the heat conducted to an insulator from clamp, $P_{\text {out }}$ is the heat conducted to the next insulator from the insulator of interest, $P_{s}$ is the head conducted to the insulator by solar radiation, and $P_{c}$ and $P_{r}$ are respectively heat dissipated from the conductor by convection and radiation, and can be defined as follows [31]

$$
\begin{aligned}
& P_{c}=D_{c}\left(T-T_{0}\right) \\
& P_{r}=D_{r}\left(T^{4}-T_{0}^{4}\right)
\end{aligned}
$$


where $D_{c}$ is the coefficient of dissipation by convection, $D_{r}$ is the coefficient of dissipation by radiation, $T$ is the temperature of an insulator, and $T_{0}$ is the ambient temperature.

For calculating the temperature of insulator, it can use the equation numerically as finite element method. However, it is difficult to exact numerical results since the proper values of coefficients of each material are not available. The above mentioned speculation will be enlightening to see the qualitative tendency of the phenomenon.

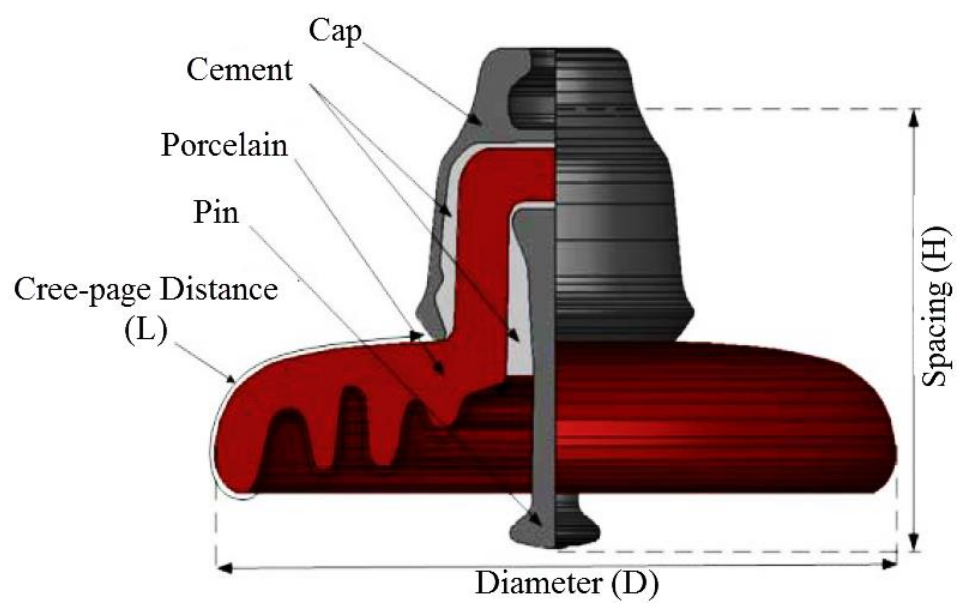

Fig.1. The tested model of a porcelain insulator disc

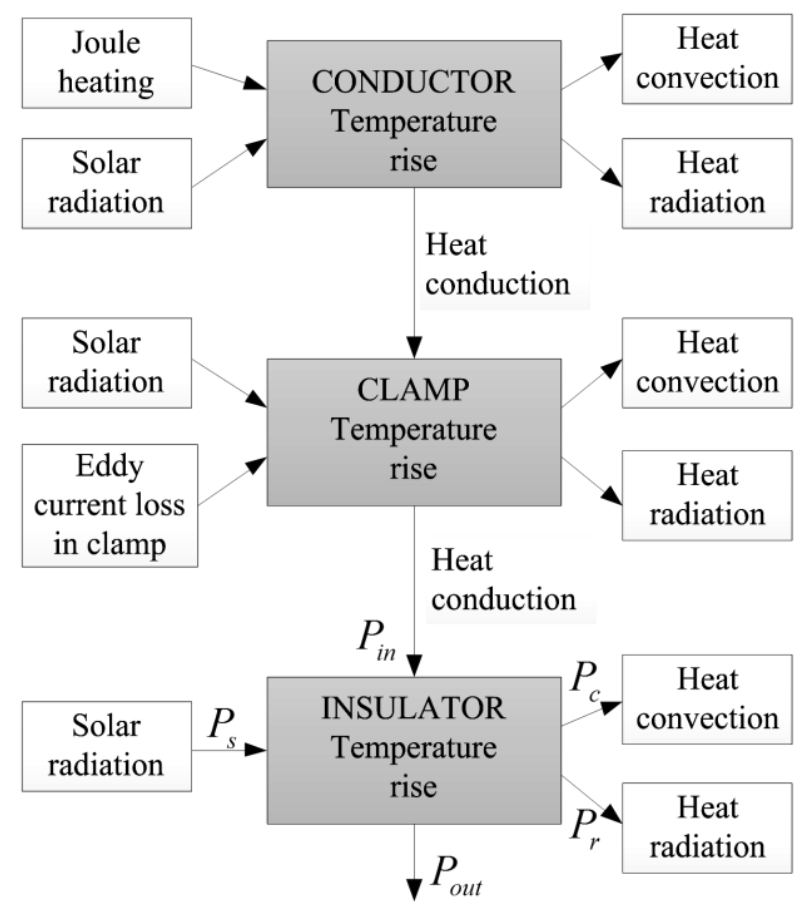

Fig. 2. The diagram of heat transfer processes

\section{EXPERIMENTAL SET-UP}

A few experimental results of temperature distribution measurement of insulators have been proposed, as conductor was heated by passing hot oil in a pipe with simulated size of a line conductor, using high direct current, or using optical fiber Bragg grating temperature sensors [32]. Alongside with these three approaches, an experiment based on a kind of non-contact remote detection technology, namely the infrared one is considered more favorable to discover the insulator string temperature distribution law. 
Fig. 3 shows a tested circuit installed in laboratory, in which A is the insulator string, B is the power supply line, and $\mathrm{C}$ is the ground wire. The used insulator string is the high voltage porcelain insulator called XP-70 type composing of 14 pieces for the suspension of $220 \mathrm{kV}$ overhead transmission lines. The tested arrangement is shown in Fig. 4, in which a transformer $110 \mathrm{~V} / 330 \mathrm{kV}$ is fed through a $380 \mathrm{~V}$ self-transformer. At one edge of the insulator string is connected a transmission line and the other edge is grounded. The technical parameters of a porcelain insulator disc are listed in Table 1.

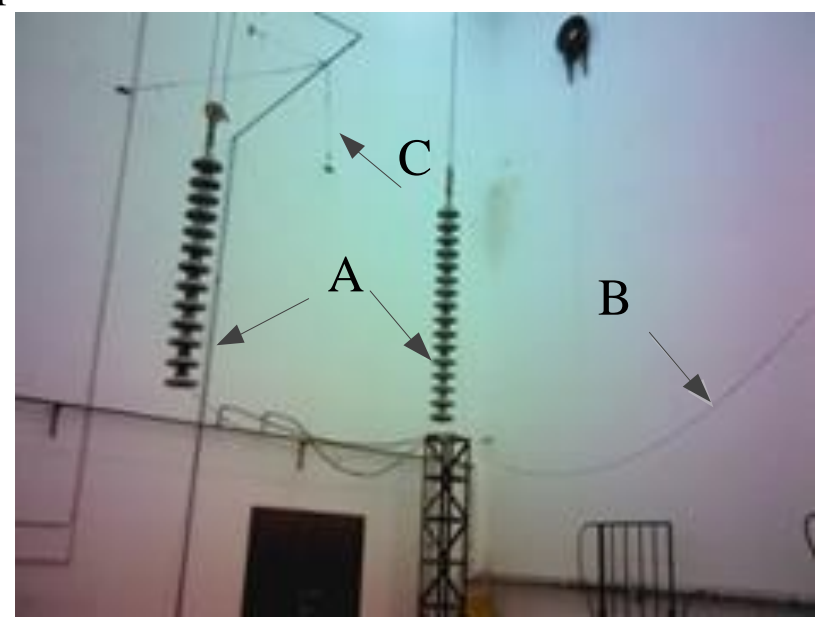

Fig. 3 Tested circuit at high voltage laboratory of College of Electrical and Information Engineering, Zhengzhou University of Light Industry, Zhengzhou, China

Table 1. Technical parameters of a porcelain insulator disc

\begin{tabular}{lcc}
\hline \multicolumn{1}{c}{ Parameters } & Unit & Value \\
\hline Unit spacing (H) & $\mathrm{mm}$ & 146 \\
Shed diameter (D) & $\mathrm{mm}$ & 255 \\
Leakage distance & $\mathrm{mm}$ & 295 \\
Weight & $\mathrm{kg}$ & 4.8 \\
Upper surface area & $\mathrm{mm}^{2}$ & 617 \\
Lower surface area & $\mathrm{mm}^{2}$ & 917 \\
total area & $\mathrm{mm}^{2}$ & 1591 \\
\hline
\end{tabular}

The experiment simulated the operation environment of $220 \mathrm{kV}$ AC power grid. The value of the single phase AC voltage was applied to the insulator string in the experiment to be $127 \mathrm{kV}$. In addition, the test chamber temperature was controlled at about $15^{\circ} \mathrm{C}$ and the relative humidity was controlled at about $55 \%$. The HZYM-500 insulator intelligent salt density tester and relative humidity sensor are used to measure online.

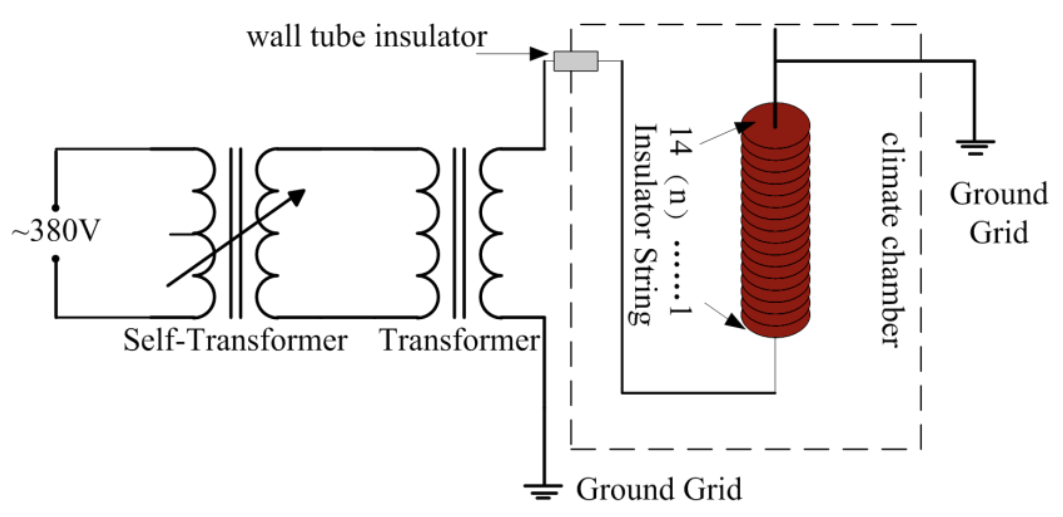

Fig. 4 Experimental set-up 


\section{RESULTS AND DISCUSSION}

The experiment was implemented on the following cases

Case 1: Determine the thermal stability time

Determining the thermal stability time of the sample insulator under the tested voltage $U_{N}$ of $127 \mathrm{kV}$, the experiment for this case was done based on the electrified conditions of the power grid, in which the insulator samples were applied on the voltage $U_{N}$ and the simulated time is about five hours with purpose to study the characteristics of the insulator temperature change and detect the required time to reach thermal stability. During the test, the ambient temperature is $15^{\circ} \mathrm{C}$ and the relative humidity id $55 \%$.

The Fig. 5 plots the temperature of porcelain changing with time 6 hours of the string. From the Fig. 5a, it can see that the surface temperature change of each the disc is very small, namely it has been proved through the $1^{\text {st }}$ and $6^{\text {th }}$ discs. And the iron cap surface temperature increases as shown in Fig. $5 \mathrm{~b}$ and this temperature is stable after 120 minutes. As result, the temperature of cap and disc cannot effectively reflect the status of insulator. There was a temperature difference between cap and disc; and the cap surface temperature had a much more powerful effect on disc one. Therefore, the cap surface temperature is chosen as the temperature characteristic of the insulator string. After the electrification about 120 minutes, the temperature of each the piece insulator in the insulator string was stabilized and it reaches a thermally stable state, as shown in Fig. 5. In this case, it could conclude that the temperature and voltage distribution of insulator are detected after the electrified 120 minutes, based on such that, the sample time $T_{s}=2$ hours will be used in the next experiment cases.

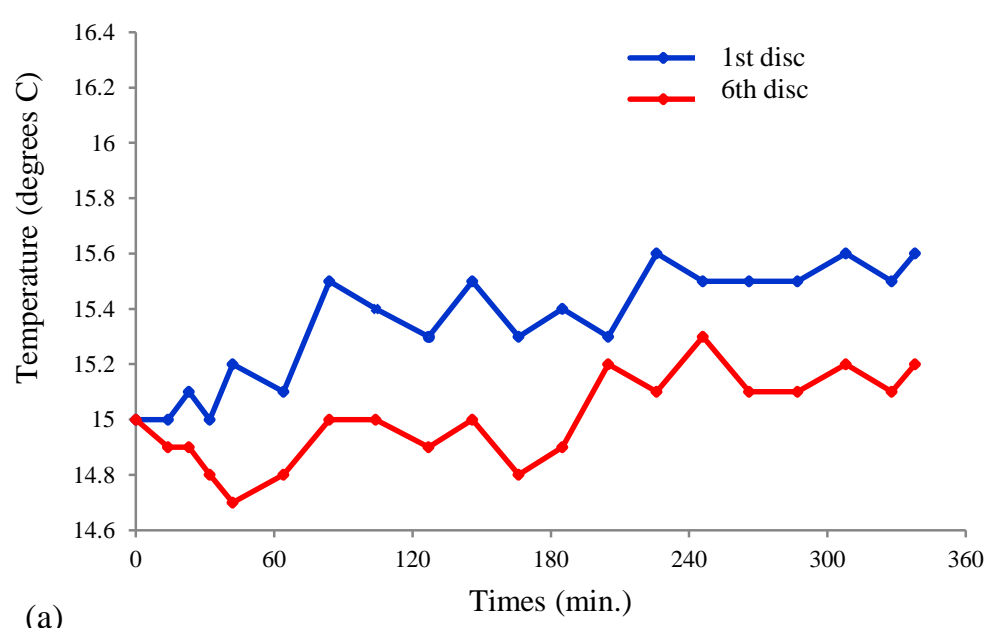

(a)

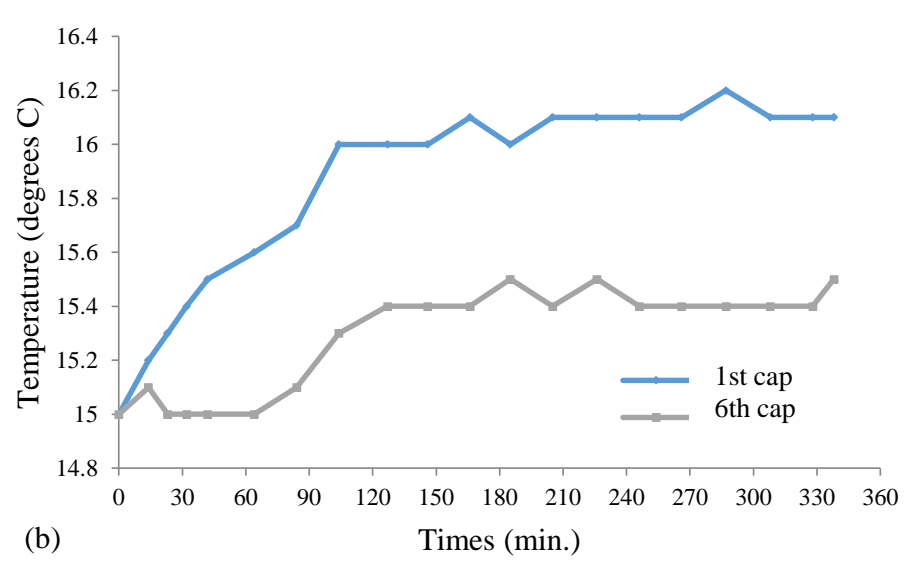

Fig. 5 The temperature of porcelain changing with time: (a) The temperature of the cap No. $1^{\text {st }}$ and $6^{\text {th }}$ insulator, (b) The temperature of the disk No. $1^{\text {st }}$ and $6^{\text {th }}$ insulator 
Case 2: The temperature distribution characteristic of a good insulator string

The experiment for this case was done using the electrified time $T_{s}$ to measure the temperature distribution and identify the temperature distribution characteristic of the insulator string not faulty insulator discs. Fig. 6 plots the voltage distribution of the insulator string. Observing this figure, the voltage on the first disc is high about $24 \mathrm{kV}$ and this voltage is towards decreasing to the ground terminal direction. In general, the voltage in the 13 and $14^{\text {th }}$ discs is gradually increased and the voltage in the $9^{\text {th }}$ and $10^{\text {th }}$ discs is lowest voltage in the whole insulator string.

The temperature distribution along the normal and fault insulator string corresponding with the voltage distribution as shown Fig. 7. Observing these figures it can see that the temperature distribution is the same as the voltage distribution, when the value of voltage increases, the temperature will be increase and vice versa. It could conclude that the temperature distribution of the insulator string is closely related to the placed voltage.

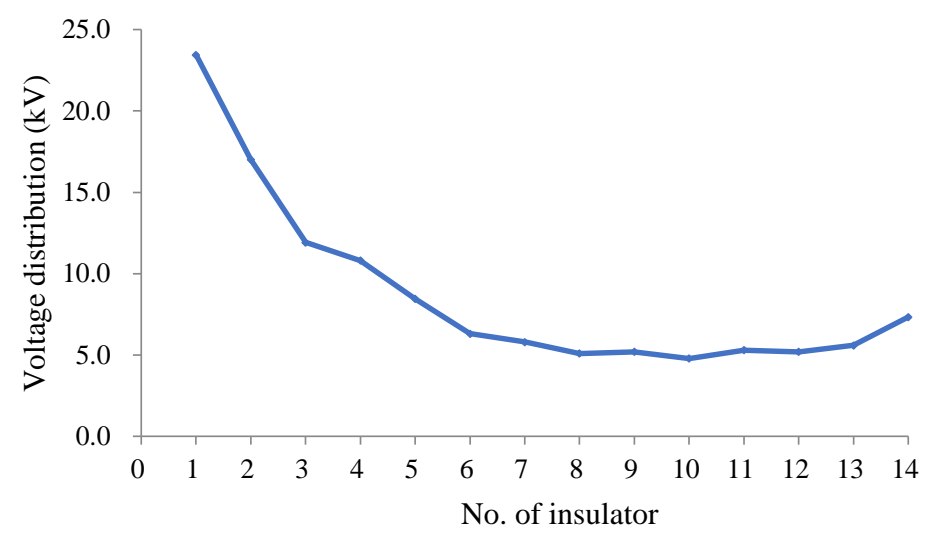

Fig. 6 Voltage distribution along the insulator string

Case 3: The temperature distribution characteristic of a fault insulator string

In order to identify the temperature distribution characteristic of the insulator string considering a faulty insulator disc, the simulation was done based on a faulty insulator disc with considering the same and different leakage resistances at the different and same positions, respectively.

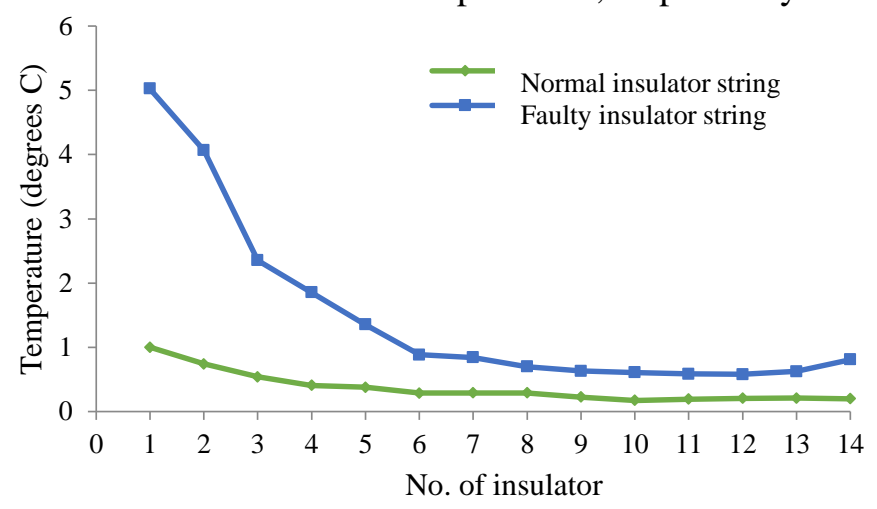

Fig. 7 Temperature distribution along the insulator string

The first experiment in this case was done to study the temperature characteristics of the faulty insulator string having a faulty disc that placed at the different positions in the string with the same resistance. Fig. 8 plots the temperature distribution along the insulator string with fault disc at three positions of No. 1, 9 and 14 with the same resistance $58.8 \mathrm{M} \Omega$. Observing this figure, it could see that the fault disc at the location closing to the wire side (disc No. 1) has the highest temperature rise, and the temperature rise decreased when the fault disc at the location closes to the ground side (disc No. 14). 


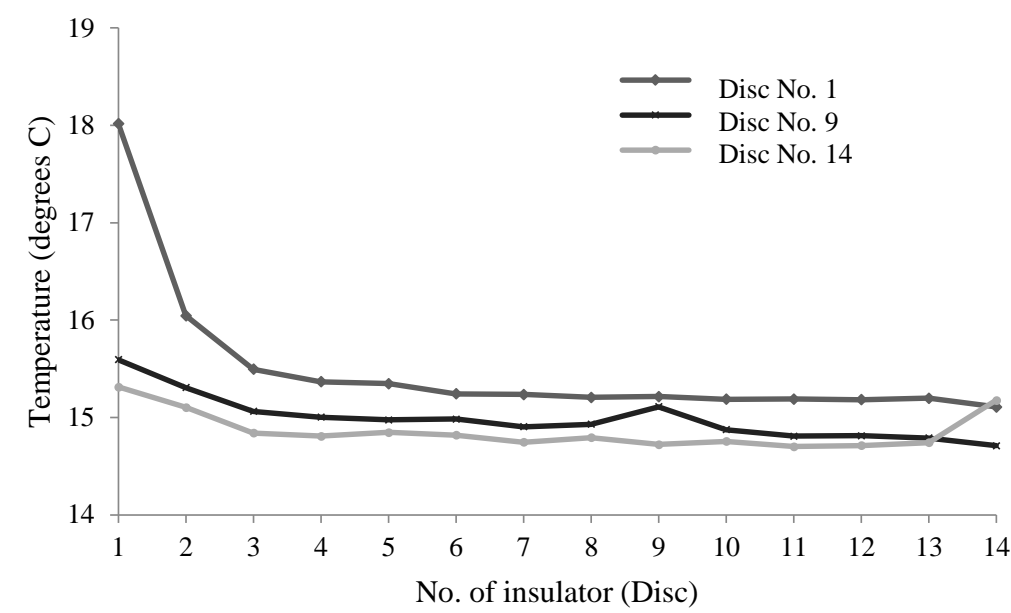

Fig. 8 Temperature distribution along the insulator string with fault disc at three positions with the same resistance $58.8 \mathrm{M} \Omega$.

The second experiment in this case was done to study the temperature characteristics of the faulty insulator string having a faulty disc that placed at the same position in the string with the different resistances. Fig. 9 plots the temperature distribution along the insulator string with fault disc at three positions of No. 1, 9 and 14 with the varied resistances. Observing this figure, it could see that the fault disc at the location closing to the wire side (disc No. 1) has the highest temperature rise, and the temperature rise decreased when the fault disc at the location closes to the ground side (disc No. 14). The temperature distribution along the insulator string having a fault insulator disc increases in value at different resistances at one position.

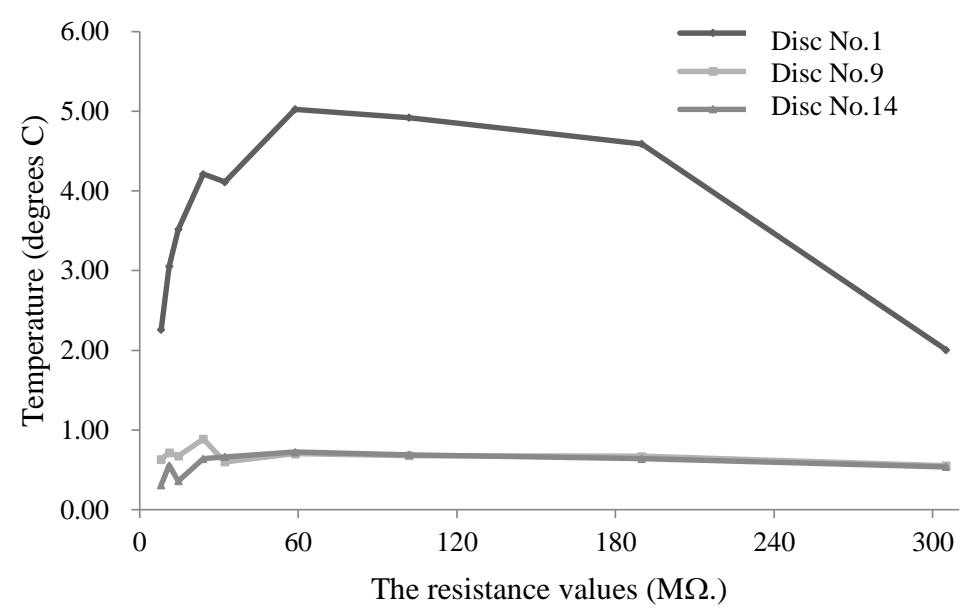

Fig. 9 Temperature distribution along the insulator string

\section{CONCLUSION}

The experimental-based studies for the temperature distributions along the semiconducting porcelain insulator string surfaces have been investigated by using a kind of non-contact remote detection technology, namely the infrared one. The experimental results show that it may detect and compare the insulator metal cap temperature of faulty insulators in the porcelain insulator string and determine the location of them. Using this technology, the time of thermal stability of the insulator is 120 minutes and reasonably fast. It concluded that the temperature distribution of the insulator string is closely related to the placed voltage. And especially based on the the unchangeable voltage distribution, it may detect the temperature distribution characteristic for the fault insulator string. Therefore, this study can provide a reference for detection of faulty insulator. 


\section{REFERENCES}

[1] Palangar, M.F.; Mirzaie, M.; and Palangar, M.F. 2015. Detecting of unnormal conditions of polluted insulators based on analysis phase angle of leakage current, In proceedings of 20th Conference on Electrical Power Distribution Networks, Zahedan, Iran, 28-29 April, pp. 7-15.

[2] Shen, X.; Jiang, X.; Cheng, Y; and MacAlpine, M.A. 2008. Novel method for live detection of faulty direct current insulators, IEEE Transactions on Power Delivery. Vol. 23, no. 1, pp. 24-30.

[3] Birlasekaran, S.; Li, H. J. 2000. Detection of faulty insulators on power transmission line. In proceedings of Power Engineering Society Winter Meeting, Singapore, Singapore, 23-27 Jan., vol. 4, pp. 2817 - 2821.

[4] Li, C. R.;Shi, Q.; Cheng, Y. C.; Lin, G.; and Xingquan, H. 1998. Identifying faulty insulator strings by detecting insulator corona pulse current, In proceedings of International Conference on Power System Technology, Beijing, China, 18-21 Aug., vol. 1, pp. 529-532.

[5] Unahalekhaka, P. and Sirichunchuen, K. 2017. Influence of Electric Field Distribution along the Line Post and Pin Post Insulator due to Lightning Strike. GMSARN International Journal, vol. 11, no. 1, pp. 23-27.

[6] Unahalekhaka, P. and Phonkaphon, S., 2014. Simulation of Potential and Electric Field Due to Defective Insulator in $115 \mathrm{kV}$ Transmission Line. GMSARN International Journal, vol. 8, no.1, pp.7-11.

[7] De Oliveira, H.R.P.M.; Batista, E.L.; Lefort, C.; De Salles, C.; and Martinez, M.L.B. 2009. Inspection of pin insulators in distribution medium voltage lines and outage reductions, In proceedings of International Symposium on Electrical Insulation, Vancouver, BC, Canada, 9-12 June, pp.524-529.

[8] Cheng, Y.; Li, C; and Huang, X. 2008. Study of corona discharge pattern on high voltage transmission lines for inspecting faulty porcelain insulators. IEEE Transactions on Power Delivery, vol. 23, no.2, pp. 945-952.

[9] Anjum, S.; El-Hag, A.; Jayaram, S.; and Naderian, A. 2014. Classification of defects in ceramic insulators using partial discharge signatures extracted from radio frequency (RF) signals, In proceedings of Electrical Insulation and Dielectric Phenomena, Des Moines, IA, USA, 19-22 Oct., pp. 212-215.

[10] Nyamupangedengu, C.; Luhlanga, L.P.; and Letlape, T. 2007. Acoustic and HF detection of defects on porcelain pin insulators. In proceedings of Power Engineering Society Conference and Exposition in Africa, Johannesburg, South Africa, 16-20 Jul, pp.1-5.

[11] Ji, Y.; Tao, X.; Jianjun, T.; Lan, X.; and Zhan-long, Z. 2007. Online detection system for contaminated insulators based on ultra-violet pulse method. In proceedings of Electrical Insulation and Dielectric Phenomena, Vancouver, BC, Canada, 14-17 Oct., pp. 558-561.

[12] Shong, K.M.; Kim, Y.S; and Kim, S.G. 2007. Images detection and diagnosis of corona discharge on porcelain insulators at $22.9 \mathrm{kV}$ D/L. In proceedings of International Symposium on Diagnostics for Electric Machines, Power Electronics and Drives, Cracow, Poland, 6-8 Sept., pp. 462-466.

[13] El-Arabaty, A.; Nosseir, A.; El-Debeiky, S., Nasser, E.; El-Sharkawi, E.; and El-sarky, A. 1979. Application of infra-red thermography to the study of temperature distribution on energized polluted insulators, IEEE Transactions on Electrical Insulation, vol. EI-14, no.5, pp. 278-280.

[14] Lang, P. G.; Allan, D. M,; Zhou, Y.; Lang, P.G.; Allan, D.M.; and Zhou, Y. 1994. The investigation of insulation defects in transmission line disc insulators using remote detection techniques, In Proceedings of 4 th International Conference on Properties and Applications of Dielectric Materials, Brisbane, Queensland, Australia, 3-8 July, vol. 2, pp. 868-871.

[15] Chan, J.S. and Fuller, K. 1979. Infra-red inspection and evaluation of motors generators and transformers, In proceedings of 14th Electrical/Electronics Insulation Conference, Chicago IL, USA, 8-11 Oct., pp. 68-71.

[16] Reid, A.J.; Zhou, C.; Hepburn, D.M.; Judd, M.D.; Siew, W.H.; and Withers, P. 2013. Fault location and diagnosis in a medium voltage EPR power cable. IEEE Transactions on Dielectrics \& Electrical Insulation, vol. 20, no.1, pp. $10-18$.

[17] Ha, H.; Han, S; and Lee, J. 2011. Fault detection on transmission lines using a microphone array and an infrared thermal imaging camera. IEEE Transactions on Instrumentation and Measurement, vol. 61, no. 1, pp.267-275.

[18] Mizuno, Y.; Naito, K.; Suzuki, Y.; Mori, S.; Nakashima, Y.; and Akizuki, M. 1999. Voltage and temperature distribution along semiconducting glaze insulator strings. IEEE transactions on dielectrics and electrical insulation, vol. 6, no. 1, pp.100-104.

[19] Vitelli, M.; Tucci, V.; and Petrarca, C. 2000. Temperature distribution along an outdoor insulator subjected to different pollution levels. IEEE Transactions on Dielectrics and Electrical Insulation, vol. 7, no. 3, pp.416-423.

[20] Reddy, B.S. and Nagabhushana, G.R. 2003. Study of temperature distribution along an artificially polluted insulator string. Plasma Science and Technology, vol. 5, no. 2, p.1715.

[21] Han, S.W.; Cho, H.G.; Choi, I.H.; and Lee, D.I. 2006. Failure characteristics of suspension-type porcelain insulators on a $154 \mathrm{kV}$ transmission line, In proceedings of International Symposium on Electrical Insulation, Toronto, Ont., Canada, 11-14 June, pp. 118-121. 
[22] Fujii, O.; Mizuno, Y.; and Naito, K. 2006. Temperature of insulators as heated by conductor. IEEE transactions on power delivery, vol. 22, no. 1, pp. 523-526.

[23] Da Costa, E.G., Ferreira, T.V., Neri, M.G., Queiroz, I.B. and Germano, A.D. 2009. Characterization of polymeric insulators using thermal and UV imaging under laboratory conditions. IEEE Transactions on Dielectrics and Electrical Insulation, vol. 16, no. 4, pp. 985-992.

[24] Bologna, F.; Mahatho, N.; and Hoch, D.A.; 2002. Infra-red and ultra-violet imaging techniques applied to the inspection of outdoor transmission voltage insulators, In proceedings of 6th Africon Conference in Africa, George, South Africa, 2-4 Oct., vol. 2, pp. 593-598.

[25] Morales, N.; Asenjo, E.; and Valdenegro, A. 2001. Field solution in polluted insulators with non-symmetric boundary conditions. IEEE Transactions on Dielectrics and Electrical Insulation, vol. 8, no. 2, pp.168-172.

[26] Zhao, T; and Comber, G. 2000. Calculation of electric field and potential distribution along nonceramic insulators considering the effects of conductors and transmission towers. IEEE Transactions Power Delivery, vol. 15 , no. 1 , pp. 313-318.

[27] Asenjo, E; Morales, N; Valdenegro, A. 1997. Solution of low frequency complex fields in polluted insulators by means of the finite element method. IEEE Transactions on Dielectrics and Electrical Insulation, vol. 4, no.1, pp. $10-16$.

[28] Sebestye'n Mire. 2002. Electric-field calculation for HV insulators using domain-decomposition method. IEEE Transactions on Power Delivery, vol. 38, no.2, pp. 1213-1216.

[29] Kontargyri, V.T.; Goons, I.F.; Ilia, N.C.; and Stathopoulos, I.A. 2004. Simulation of the electric field on composite insulators using the finite elements method, Proc. of the 8th WSEAS World Multiconference on Circuits, Systems Communications and Computers. pp. 487-726.

[30] Zhang, B.; Jinliang, H.; Xiang, C.; Shejiao, H.; and Zou, J. 2006. Electric Field Calculation for HV Insulators on the Head of Transmission Tower by Coupling CSM with BEM. IEEE Transaction on magnetics, vol. 42, no.4, pp. 543-546.

[31] Palhade, R.D.; Tungikar, V.B.; Dhole, G.M.; and Kherde, S.M.; 2013. Transient thermal conduction analysis of voltage cap and pin type ceramic disc insulator assembly. International journal of advanced science and technology, vol. 13, pp. 73-85

[32] Zhao, C.J.; Li, C.; Zhang, X.; Zhao, Z.G.; Li, Y.N.; and Xie, T. 2013. Temperature researches of porcelain insulator. Transactions Technology Publications in Advanced Materials Research, vol. 718, pp. 1734-1739.

\section{NGHIÊN CỨU PHÂN BỐ NHIẸTT CỦA CHUỔI CÁCH ĐIỆN XÚ̉ ĐIỆN ÁP CAO}

Tóm tắt. Ngày nay, chuổi cách điện sứ thường được sử dụng rộng rãi cho cách điện đường dây truyền tải cao áp. Thiết kế cũng như phát triển thiết bị cách điện ở cấp điện áp cao thì việc nghiên cứu phân bố nhiệt trên chuổi cách điện là cần thiết. Như được biết, kỹ thuật sử dụng tia hồng ngoại đã mở ra một loạt ứng dụng và đặc biệt là sử dụng như một kỹ thuật điều khiển từ xa không tiếp xúc. Kỹ thuật này có tối ưu là phát hiện chuổi cách điện sứ bị lỗi. Bài báo này sử dụng kỹ thuật hồng ngoại với mục đích chính là nghiên cứu phân bố nhiệt của chuổi cách điện với cấp điện áp $220 \mathrm{kV}$. Thứ nhất, xác định thời gian ổn định nhiệt của loại chuổi cách điện XP-70 có 14 đĩa với điện áp thí nghiệp là $127 \mathrm{kV}$ dựa trên sự phân bố nhiệt và điện áp. Thứ hai, phân bố nhiệt của chuổi cách điện bình thường và lỗi cũng được mang ra để nghiên cứu và so sánh. Kết quả thí nghiệm cho thấy rằng phương pháp đề xuất có thể dò tìm và so sánh nhiệt của khe hở giữa có đĩa sứ trong một chuổi sứ cách điện của chuổi cách điện bị lỗi và xác định ra vị trí của chúng và đặc biệt, dựa trên sư phân bố điện áp không đổi, thì phương pháp đề xuất có thể dò tìm đặc tính phân bố nhiệt của chuổi sứ bị lỗi. Vì vậy, kết quả nghiên cứu này có thể cung cấp sự tham khảo trong việc dò tìm những chuổi cách điện bị lỗi.

Từ khóa. Kỹ thuật hồng ngoại, phân bố nhiệt độ, phân bố điện áp, chuổi cách điện sứ

Ngày nhận bài: 9/9/2019

Ngày chấp nhận đăng: 17/01/2020 